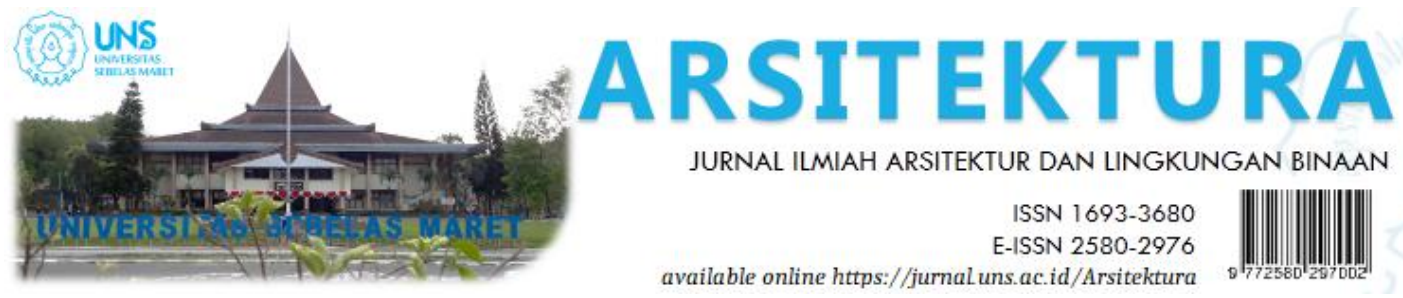

Volume 17 Issue 2 October 2019, pages:151-158

\title{
Strategi Penerapan Sistem Keamanan Pada Desain Lembaga Pemasyarakatan Kelas II Di Surakarta
}

\section{Security System Implementation at The Second Level of Panitentiary Design Strategy in Surakarta}

\author{
Reysa Yanarsya Putri ${ }^{1 *}$, Rachmadi Nugroho ${ }^{2}$, Agung Kumoro Wahyuwibowo ${ }^{3}$ \\ Program Studi Arsitektur, Fakultas Teknik, Universitas Sebelas Maret ${ }^{1}$ \\ Email : reysayanarsya@gmail.com* \\ Program Studi Arsitektur, Fakultas Teknik, Universitas Sebelas Maret ${ }^{2}$ \\ Program Studi Arsitektur, Fakultas Teknik, Universitas Sebelas Maret ${ }^{3}$
}

DOI: https://doi.org/10.20961/arst.v17i2.23508

Received: September 6, 2018 Revised : October 4,2018 Accepted: March 30,2019 Available online:October 31, 2019

\begin{abstract}
The role of level II prison in Surakarta as a supporter of the correctional system is based on three aspects. The first aspect is to overcome the problem of prisoners' excess capacity in Indonesia by building prisons in every district or city so that the handling and placement of prisoners are at their place of origin. Second, Surakarta is a city that contributes to the second highest crime rate in Central Java and the lack of optimal correctional facilities that already exist. Third, the security aspects are the most important factor in establishing prison buildings, because in this era, security is not only done manually but also electronically. The combination of the two security systems can provide the concept of a more modern prison design. The discussion method applied from the beginning to the completion of the design is through the stages of problem identification and exploration, stages of data collection through precedent studies, interviews, observations, and security system theory literature. Then the analysis stages that combine data obtained with theories related to prison buildings. The results of the overall analysis include five concepts of designing prison security system design concepts in the form of deter, detect, delay, halt, and minimize.
\end{abstract}

Keywords: prisoner, prison, security system

\section{PENDAHULUAN}

Pada saat ini kondisi Lapas di Indonesia, memilki beberapa kendala. Kendala paling utama adalah over kapasitas Lapas yang menyebabkan melemahnya fasilitas pembinaan dan sistem keamanan bagi narapidana. Kendala ini juga memunculkan pendapat dari Direktur Jendral Lapas Kementrian HAM bahwa Indonesia diharapkan disetiap kabupaten atau kota memiliki Lembaga Pemasyarakatan demi mengurangi angka over kapasitas Lapas. Dengan demikian, penghuni Lapas dapat di tempatkan dan ditangani sesuai dengan kabupaten atau kota asalnya (Sutisna, 2017).

Pada kota di wilayah Jawa Tengah, Kota Surakarta menyumbangkan tindak kejahatan pidana tertinggi ke dua dari kota-kota lain. Terdapat data jumlah perkara kasus pidana terselesaikan di Kota Surakarta, telah mengalami peningkatan dari tahun 2012 sejumlah 466 perkara sampai tahun 2016 
sejumlah 841 perkara (Bapppeda Kota Surakarta, 2016). Hal ini berakibat diterapkannya sanksi penjara dan/ denda untuk penyelesaiannya. Narapidana di Kota Surakarta secara tidak langsung menunjukan jumlah yang tinggi dari data jumlah perkara kasus pidana, sehingga membutuhkan wadah yang tepat bagi keberadaan narapidana tersebut berupa Lapas.

\subsection{Fasilitas Pemasyarakatan Narapidana di Kota Surakarta}

Keberadaan Rutan di Kota Surakarta sebagai satu-satunya wadah pemasyarakatan dalam menangani narapidana juga mengalami permasalahan over kapasitas. Menurut pemaparan Kepala Kanwil Kemenkumham Jateng Bambang Sumardiono menjelaskan bahwa pada Provinsi Jawa Tengah, 18 Rutan dan 11 Lapas terjadi kelebihan kapasitas, angka tertinggi terjadi di Rutan kelas I Surakarta dan Lapas Kedungpane (Purbaya, 2017).

Data jumlah narapidana yang ada pada Rutan juga menunjukan peningkatan dari tahun 2015 (bulan Desember) berjumlah 288 orang sedangkan pada tahun 2018 (bulan Maret) berjumlah 308 orang (Direktorat Jendral Pemasyarakatan, 2018). Kemudian ditambah kondisi bangunan Rutan yang tidak bisa diperluas lagi membuat kapasitas pengguna rutan tidak dapat bertambah. Hal ini, menimbulkan permasalahan penyimpangan perilaku yang dilakukan narapidana dan pemindahan narapidana ke Lapas lain di luar wilayah Surakarta.

Keberadaan fasilitas pemasyarakatan di Kota Surakarta yang belum terpenuhi dapat menjadi pertimbangan perlunya wadah lembaga pemasyarakatan yang memerlukan sebuah metode desain agar permasalahanpermasalahan dapat terselesaikan secara arsitektural. Penerapan sistem keamanan dipilih sebagai penekanan dalam perencanaan dan perancangan lembaga pemasyarakatan.

\subsection{Aspek Sistem Keamanan Lembaga Pemasyarakatan}

Aspek sistem keamanan merupakan pembahasan yang memang diperlukan dalam setiap perancangan bangunan, namun pengaplikasian antar bangunan berbeda-beda tergantung dari fungsinya (Angkasa, R. R., Nugroho, Rachmadi, \& Pradnya, 2014). Secara umum konsep desain sistem keamanan bangunan dapat dikategorikan menjadi empat (National Crime Prevention Council, 2008) yaitu: Teritorialias yaitu keamanan pengguna, Natural surveillance yaitu keamanan lingkungan dan kondisi fisik bangunan, Natural access control yaitu keamanan terkait hubungan antara penggunan bangunan dengan orang lain, Maintenance dan management yaitu keamanan dalam menjalankan sistem pengelolaan yang terorganisasi.

Bangunan Lembaga Pemasyarakatan salah satu hal yang membutuhkan keamanan yang ekstra terkait dengan fungsi bangunan dan perilaku pengguna di dalamnya. Aspek keamanan Lapas memerlukan pengaplikasian secara khusus dengan menggabungkan komponen arsitektural, agar membentuk sistem keamanan yang lebih efektif. Sistem Keamanan Lapas diperoleh dari penggabungan antar standar yang diterapkan oleh pemerintah, ketentuan dari sistem keamanan secara manual ataupun elektronik, dan bentuk arsitektural pada bangunan. Terdapat lima prinsip desain sistem keamanan lapas yang tetap terkombinasikan dengan pengelolaan dan keamanan nyawa penggunanya (Phillips, Todd S., Kliment, Stephen A., \& Griebel, 2003) antara lain:

\section{a. Penghalang (deter)}

Keberadaan penghalang memungkinkan untuk meminimalkan ancaman yang dapat mengganggu kegiatan di dalam area bangunan dan memberikan efek jera.

\section{b. Pemeriksaan (detect)}

Mendeteksi setiap kegiatan yang berada di lingkungan bangunan oleh pengelola untuk memberikan perlindungan dan identifikasi terhadap kegiatan yang sedang terjadi.

\section{c. Penundaan (delay)}

Memperlambat pergerakan kegiatan sebagai respon sistem bangunan dengan situasi.

\section{d. Penghentian (halt)}

Mengontrol kegiatan yang akan dilakukan pengguna bangunan sebelum hal tersebut dilakukan. 


\section{e. Memperkecil (minimize)}

Meminimalkan atau dapat menghilangkan apabila terjadi kerusakan atau ancaman yang timbul dari lingkungan sekitar bangunan.

\subsection{Lembaga Pemasyarakatan}

Lembaga Pemasasyarakatan atau Lapas menurut UU No.12 Tahun 1995 tentang Pemasyarakatan (Kementrian Sekertaris Negara Republik Indonesia, 1995), menjadi wadah dalam membentuk narapidana atau warga binaan pemasyarakatan agar menjadi manusia seutuhnya, menyadari kesalahan, memperbaiki diri, dan tidak mengulangi tindak pidana sehingga dapat diterima kembali oleh lingkungan masyarakat, dapat aktif berperan dalam pembangunan, dan dapat hidup secara wajar sebagai warga yang baik dan bertanggung jawab. Untuk penunjang proses pemasyarakatan dapat diwujudkan melalui beberapa aktivitas yang dilakukan dan hubungan yang baik antara tiga pelaku pemasyarakaran yaitu petugas pengelola, narapidana, dan masyarakat (B. Prasetya, Andhika., Purnomo, M.D.E., \& Widodo, 2015). Menurut Keputusan Menteri Kehakiman Republik Indonesia No. M. 02Pk.04.10 Tahun 1990 tentang pola pembinaan narapidana/tahanan (Menteri Kehakiman Republik Indonesia, 1990), aktivitas yang perlu diwadahi oleh sebuah bangunan Lapas adalah sebagai berikut:

a. Aktivitas kunjungan, untuk memberi kesempatan keluarga, masyarakat, dan instansi terkait untuk bertemu dengan narapidana dengan izin.

b. Aktivitas administrasi, penyelenggaraan untuk koordinasi dengan seluruh pengguna bangunan Lapas.

c. Aktivitas pembinaan, kegiatan yang dilakukan dalam proses pembinaan kepribadian dan pembinaan kemandirian bagi narapidana.

d. Aktivitas penunjang, kegiatan yang menunjang segalanya di dalam lapas.

e. Aktivitas pelayanan, kegiatan pemeliharaan dan penyediaan sarana prasarana untuk narapidana.

f. Aktivitas hunian, kegiatan yang mencakup kehidupan sehari-hari narapidana berupa, tidur, makan, istirahat, dan bersantai.

\section{METODE}

Metode pembahasan sebagai dasar pengerjaan melalui beberapa tahapan yaitu mulai dari pengumpulan data sampai dengan analisis data terhadap perencanaan dan perancangan bangunan Lembaga Pemasyarakatan Kelas II di Kota Surakarta dengan menerapkan kajiankajian dalam teori sistem keamanan.

Tahap pertama, identifikasi masalah dan eksplorasi yang didapat dari mencari isu-isu permasalahan mengenai pengguna dan perilaku di dalam bangunan Lapas.

Tahap kedua, pengumpulan data yang akan menjadi pertimbangan dalam keputusan desain bangunan Lapas Kelas II di Kota Surakarta. Metode pengumpulan data dilakukan dengan studi preseden, wawancara, observasi guna mendapatkan kebutuhan ruang dan kegiatan yang dilakukan, dan studi literatur terhadap teori elemen bangunan Lapas dan teori sistem keamanan bangunan Lapas.

Tahap ketiga, analisis data dengan cara mendapatkan kesesuaian prinsip-prinsip teori sistem keamanan yang dapat diterapkan pada bangunan Lapas. Prinsip-prinsip tersebut diolah kembali untuk menetapkan strategi perancangan yang dapat menjawab persoalan desain. Kemudian pada proses penyajian data dilakukan dengan cara memaparkan data dalam bentuk narasi.

\section{HASIL DAN PEMBAHASAN}

\subsection{Aplikasi Prinsip Keamanan dan Konsep Perancangan}
a. Penghalang (deter)
b. Pemeriksaan (detect)
c. Penundaan (delay)
d. Penghentian (halt)
e. Memperkecil (minimize)

\subsection{Peruangan}

Kebutuhan ruang pada Lapas didasarkan pada pengguna kegiatan, program kegiatan, dan kebutuhan besaran ruang.

Pengguna kegiatan yang terlibat pada Lapas antara lain pengelola Lapas, warga binaan Pemasyarakatan, pengunjung yang meliputi keluarga, masyarakat, dan instansi terkait. 
Kegiatan dari pengguna tersebut membutuhkan ruang khusus di dalamnya. Pada pengelola Lapas mencakup kegiatan regristrasi, administrasi, kunjungan dan pelayanan. Pada warga binaan pemasyarakatan mencakup kegiatan hunian, pembinaan, dan kunjungan. Pada pengunjung mencakup kegiatan kunjungan. Secara rinci dapat dilihat pada Tabel 1.

Tabel 1. Kebutuhan Ruang Lapas

\begin{tabular}{|c|c|}
\hline Kelompok Ruang & Ruang \\
\hline \multicolumn{2}{|c|}{ Kelompok Kegiatan Penerima } \\
\hline \multirow[t]{7}{*}{$\begin{array}{l}\text { Kelompok Ruang } \\
\text { pengelola }\end{array}$} & $\begin{array}{l}\text { Ruang regristrasi dan } \\
\text { bimbingan }\end{array}$ \\
\hline & Ruang unit perawat \\
\hline & $\begin{array}{l}\text { Ruang unit latihan dan } \\
\text { erja produksi }\end{array}$ \\
\hline & $\begin{array}{l}\text { Ruang unit pengamat } \\
\text { pemasyarakatan }\end{array}$ \\
\hline & Hunian Dinas \\
\hline & Parkir pengelola \\
\hline & Parkir pengujung \\
\hline \multirow[t]{2}{*}{$\begin{array}{l}\text { Kelompok Ruang } \\
\text { kunjungan }\end{array}$} & $\begin{array}{l}\text { Ruang portir dan } \\
\text { penerima }\end{array}$ \\
\hline & Ruang kunjungan \\
\hline \multicolumn{2}{|c|}{ Kelompok Kegitan Penunjang } \\
\hline \multirow{4}{*}{$\begin{array}{l}\text { Kelompok Ruang } \\
\text { penunjang }\end{array}$} & Ruang poliklinik \\
\hline & Ruang dapur \\
\hline & Ruang ME \\
\hline & Garasi \\
\hline \multicolumn{2}{|c|}{ Kelompok Kegiatan Pembinaan } \\
\hline \multirow[t]{6}{*}{$\begin{array}{l}\text { Kelompok Ruang } \\
\text { pembinaan }\end{array}$} & $\begin{array}{l}\text { Ruang pembinaan } \\
\text { keagamaan }\end{array}$ \\
\hline & $\begin{array}{l}\text { Ruang pembinaan } \\
\text { intelektual }\end{array}$ \\
\hline & Ruang pembinaan fisik \\
\hline & $\begin{array}{l}\text { Ruang pembinaan } \\
\text { kesenian }\end{array}$ \\
\hline & $\begin{array}{l}\text { Ruang pembinaan } \\
\text { kemandirian }\end{array}$ \\
\hline & $\begin{array}{l}\text { Ruang pembinaan } \\
\text { integrasi dengan } \\
\text { masyarakat }\end{array}$ \\
\hline \multicolumn{2}{|c|}{ Kelompok Kegitan Hunian } \\
\hline \multirow{4}{*}{$\begin{array}{l}\text { Kelompok Ruang } \\
\text { Hunian }\end{array}$} & Kamar Tidur \\
\hline & Pos Jaga \\
\hline & Ruang Bersama \\
\hline & Ruang Jemuran \\
\hline
\end{tabular}

Kebutuhan ruang pada fasilitas bangunan Lapas menghasilkan kebutuhan luasan ruang bangunan, yaitu: (lihat pada Tabel 2).
Tabel 2. Kebutuhan Luasan Ruang Lapas

\begin{tabular}{|l|r|}
\hline \multicolumn{1}{|c|}{ Kelompok Ruang } & \multicolumn{1}{c|}{ Luasan $\left(\mathbf{m}^{\mathbf{3}}\right)$} \\
\hline Ruang Penerimaan & $\pm 5.339,34$ \\
\hline Ruang Penunjang & $\pm 897,32$ \\
\hline Ruang Pembinaan & $\pm 5.762,25$ \\
\hline Ruang Hunian & $\pm 4.028,64$ \\
\hline TOTAL & $\mathbf{1 6 . 0 2 7 , 5 5}$ \\
\hline
\end{tabular}

\subsection{Tapak}

Pemilihan tapak didasarkan pada fungsi bangunan yang memiliki kecenderungan lokasi jauh dari permukiman penduduk. Tapak terpilih berada di JL. Ring Road, Kel.Mojosongo, Kec.Jebres. Memiliki luas lahan $\pm 24.788,8 \mathrm{~m}^{2}$ dengan batas-batas pada sisi sebelah utara JL.Ring Road, sebelah timur dan selatan lahan kosong, sebelah barat JL.Sindoro Raya (lihat pada Gambar 1).

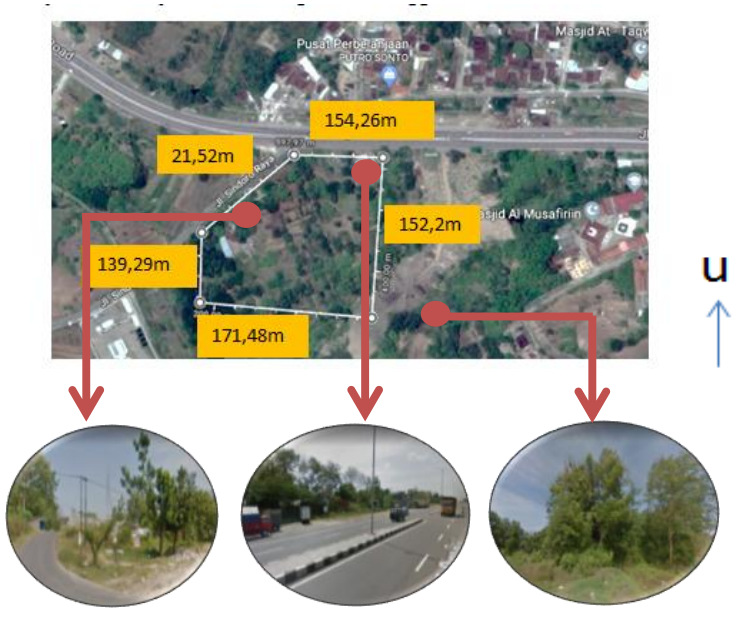

Gambar 1. Tapak Terpilih

Pengolahan tapak terhadap lingkungan fisik dicapai dengan penerapan kajian prinsip desain sistem keamanan deter, minimize, dan delay yang dilakukan dengan analisis sirkulasi dan zona, kenyamanan termal, lingkungan tapak dan sirkulasi untuk mendapatkan ketepatan respon desain terhadap kondisi tapak.

Analisis sirkulasi tapak dilakukan bertujuan untuk menentukan main entrance (ME) jalur masuk dan keluar menuju tapak yang sesuai dengan kondisi di lingkungan sekitar. Penentuan ME dipengaruhi oleh sirkulasi dan arah pergerakan lalu lintas pada tapak (lihat pada Gambar 2). 


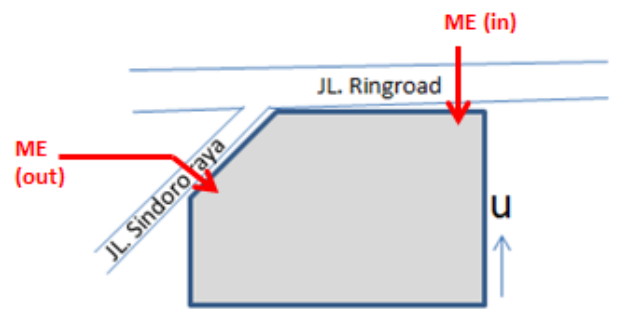

Gambar 2. Respon Main Entrance pada Tapak

Pembagian zona terdiri dari zona publik, zona pengelola, zona pembinaan, dan zona hunian. Untuk peletakan zona hunian bagi warga binaan pemasyarakatan lebih menekankan sistem keamanan maksimum, sehingga zona horizontal diletakkan pada bagian paling belakang dan pada zona vertikal diletakkan pada bagian paling atas (lihat pada Gambar 3)

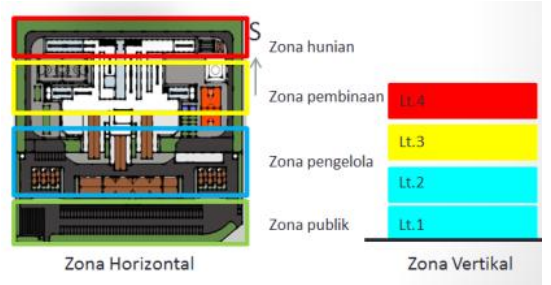

Gambar 3. Respon Zona pada Tapak

Analisis kenyamanan termal dan lingkungan akan meliputi analisis angin, matahari, dan kebisingan lingkungan. Analisis sirkulasi angin dilakukan untuk memberikan kenyamanan penghawaan bangunan dengan menentukan respon desain agar angin dapat masuk ke seluruh bangunan dalam tapak.

Analisis sinar matahari dilakukan untuk memberikan kenyamanan bangunan dalam konfigurasi ruang dan massa bangunan agar keberadaan sinar matahari tidak mengganggu kenyamanan pelaku kegiatan dalam bangunan. Strategi perancangannya yaitu tapak sebelah utara dijadikan arah orientasi bangunan, tapak bagian timur, barat, dan selatan diberi vegetasi (lihat pada Gambar 4).

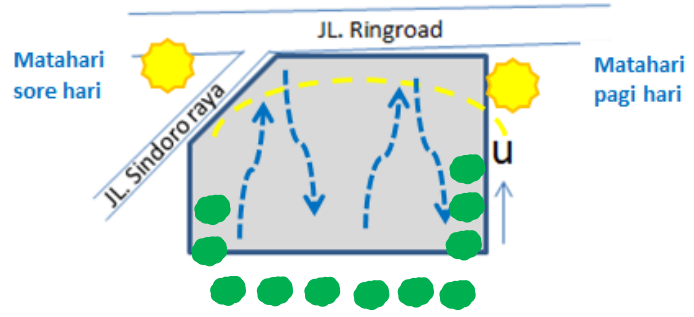

Gambar 4. Respon Tapak terhadap Kenyamanan Termal
Analisis kebisingan bertujuan untuk mengantisipasi kebisingan dari luar tapak terhadap ruang tertentu yang membutuhakn ketenangan dan tingkat kebisingan rendah. Strategi perancangannya yaitu dengan memberikan tembok pagar dan vegetasi untuk mengurangi kebisingan pada sebelah utara dan barat tapak (lihat pada Gambar 5).

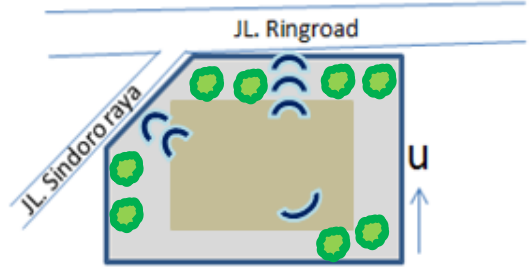

Gambar 5. Respon Tapak terhadap Kebisingan

\subsection{Tampilan Bangunan}

Analisis bentuk dasar ruang dan massa bangunan menerapkan prinsip desain sistem keamanan detec, minimize. Bentuk dasar ruang ditetapkan bentuk segi empat karena bentuk tersebut menciptakan bangunan yang formal dan mudah dipahami. Untuk bangunan utama menerapkan bentuk $U$, hal ini menunjukan pusat dibagian tengah yang terbuka sebagai tempat berkumpul dan mendukung pembinaan secara fisik dan keagamaan.

Massa bangunan secara keseluruhan menerapkan massa majemuk, namun pada area blok lapas agar pengawasan lebih mudah dan kegiatan tetap berlangsung sepanjang waktu tanpa tergantung cuaca menerapkan massa tunggal (lihat pada Gambar 6).

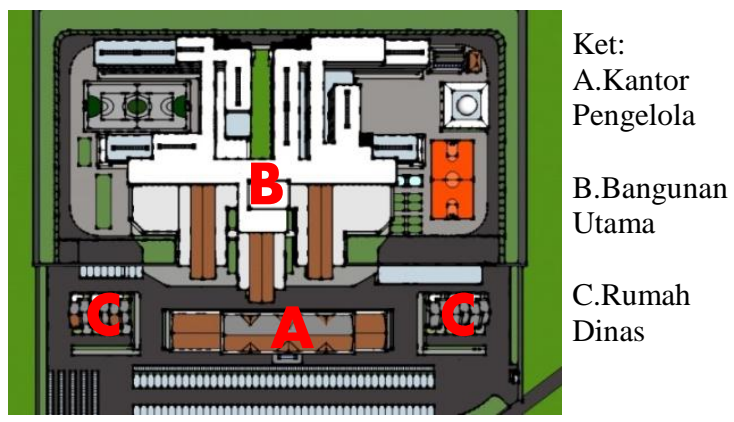

Gambar 6. Perletakan Massa Bangunan

Analisis tampilan bangunan menerapkan prinsip sistem keamanan deter, detect, minimize. Tampilan bangunan yang mendukung tercapainya keamanan yaitu dengan meletakkan kantor pengelola di depan bangunan utama agar apabila terjadi permasalahan pada bangunan utama tidak 
menyebar (lihat pada Gambar 7), memberikan bukaan yang disesuaikan dengan ukuran dan pemilihan warna dominan abu-abu, material yang aman dan tahan terhadap ancaman bencana.

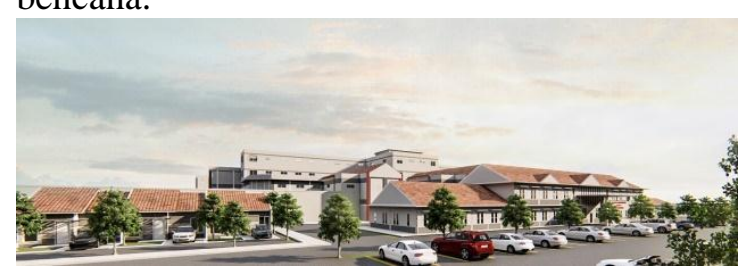

Gambar 7. Perletakan Kantor Pengelola

Analisis lansekap menerapkan prinsip desain sistem keamanan minimize, detect, delay, dan deter. Strategi pengolahan lansekap adalah pemberian vegetasi dengan ukuran sedang dan tidak terlalu rimbun, pagar pembatas berupa tembok yang mengelilingi tapak, terdapat sirkulasi kendaraan dan pejalan kaki (lihat pada Gambar 8).

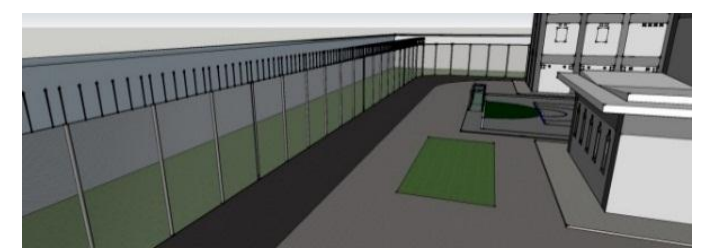

Gambar 8. Pengolahan Lansekap pada Bangunan Lapas

Analisis tata ruang bangunan lapas mempertimbangkan sistem keamanan detect, delay. Tata ruang yang diterapkan adalah linear pada pengawasan yang diletakan pada setiap kelompok ruang dengan penyesuaian bentuk dan komponen pendukung lainnya sesuai dengan fungsi ruang.

\subsection{Interior Ruangan}

Interior ruang ditekankan pada sisi fungsional dan sistem keamanan minimize, detect, halt. Strategi perancangannya dapat memberikan perabotan yang aman dan pemasangan secara tertanam, penataan layout ruang yang mempertimbangkan kemudahan pengawasan (lihat pada Gambar 9).



Gambar 9. Layout Ruang Hunian Narapidana

\subsection{Sistem Utilitas}

Strategi perancangan utilitas menerapkan prinsip desain sistem keamanan detect dan halt. Bangunan Lapas dilengkapi dengan pencahayaan buatan berupa lampu LED dan spotlight berwarna putih untuk memberikan kenyamanan serta pengawasan terhadap kegiatan Lapas. Penghawan buatan berupa AC split pada ruang pengelola. Transportasi vertikal pada bangunan lapas menerapkan tangga dan lift. Penggunaan lift diperuntukan oleh pengelola lapas saja pada bangunan utama, untuk memudahkan respon dalam mengidentifikasi ancaman dan memberikan pelayanan narapidana (lihat pada Gambar 10).

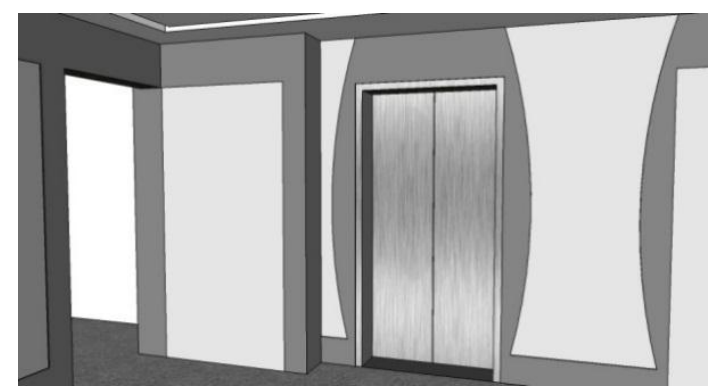

Gambar 10. Penggunaan Lift

Bangunan Lapas dilengkapi dengan sistem keamanan elektronik berupa cctv, detektor manusia dan barang, bloking sinyal jaringan, fingeprint dan face ID, serta gelang elektronik.

Sistem pemipaan pada bangunan Lapas di letakan pada plafon (enternit) dan di atas plat struktur dengan meninggikan lantainya (lihat pada Gambar 11). Pemipaan dibedakan menjadi sistem air bersih, sistem air buangan, yang terdiri dari air kotor dan air sanitasi.

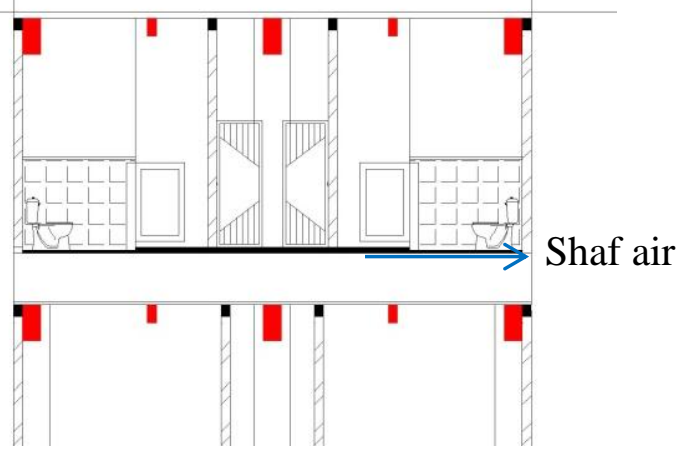

Gambar 11. Detail Pemipaan pada Atas Plat Struktur 


\subsection{Sistem Struktur}

Pemilihan material struktural dan sistem struktur menerapkan prinsip desain sistem keamanan minimize. Material struktural pada bangunan Lapas menggunakan material beton bertulang agar mampu menahan beban baik secara vertikal maupun horizontal, mudah diolah dan murah dalam perawatannya.

Sistem struktur yang digunakan mempertimbangkan kekuatan menahan beban, mudah dalam membentuk tampilan bangunan, dan yang paling penting adalah aman dari ancaman.

Sistem struktur upper struktur menggunakan atap rangka baja konvensional dengan penutup genteng tanah liat digunakan pada area pengelola. Kombinasi atap datar dengan penutup plat beton dengan skylight rangka baja lapis kaca digunakan pada bangunan utama Lapas (lihat pada Gambar 12). Sistem struktur supper struktur menggunakan struktur rangka. Sistem struktur sub struktur menggunakan pondasi tiang pancang pada bangunan 4 lantai, footplat untuk 2 lantai dan pondasi batu kali untuk bangunan tunggal dan talut.

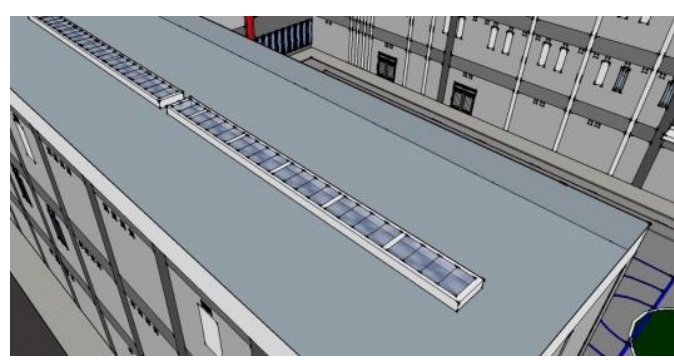

Gambar 12. Skylight sebagai Jalan Masuk Cahaya Alami dari Matahari

\subsection{Hasil Akhir}

Lembaga Pemasyarakatan Kelas II di Kota Surakarta yang memfokuskan pada sistem keamanan agar dapat memudahkan pengidentifikasi ancaman. Prinsip-prinsip sistem keamanan yang dipadukan dengan perangkat keamanan elektronik dapat diaplikasikan pada setiap persoalan desain dan diharapkan dapat menerapkan sistem keamanan maksimum secara efektif dan efisein.

Metode perencanaan dan perancangan sistem keamanan dan proses analisis yang dilakukan menghasilkan rancangan Lembaga Pemasyarakatan Kelas II di Kota Surakarta dengan penekanan Sistem Keamanan (lihat pada Gambar 13, 14, 15,16) sebagai berikut:

$\begin{array}{lll}\begin{array}{l}\text { Nama } \\ \text { bangunan } \\ \text { Lokasi }\end{array} & : & \begin{array}{l}\text { Lembaga Pemasyarakatan } \\ \text { Kelas II }\end{array} \\ & : \begin{array}{l}\text { Jalan Ring Road, Kelurahan } \\ \text { Mojosongo, Kecamatan }\end{array} \\ & \begin{array}{l}\text { Jebres, Kota Surakarta. } \\ \text { Luas }\end{array} & \pm 24.788,8 \mathrm{~m}^{2} \\ \text { lahan } & : & \pm 16.027,55 \mathrm{~m}^{2} \\ \begin{array}{l}\text { Luas } \\ \text { bangunan } \\ \text { Kegiatan }\end{array} & : & \begin{array}{l}\text { administrasi, kunjungan, } \\ \text { pembinaan, penunjang, } \\ \end{array} \\ & \text { pelayanan, dan hunian. }\end{array}$

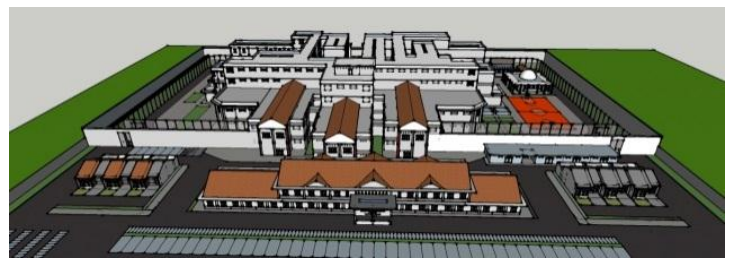

Gambar 13. Perspektif Keseluruhan Bangunan



Gambar 14. Perspektif Eksterior Area Pengelolaan



Gambar 15. Perspektif Eksterior Area Bangunan Lapas

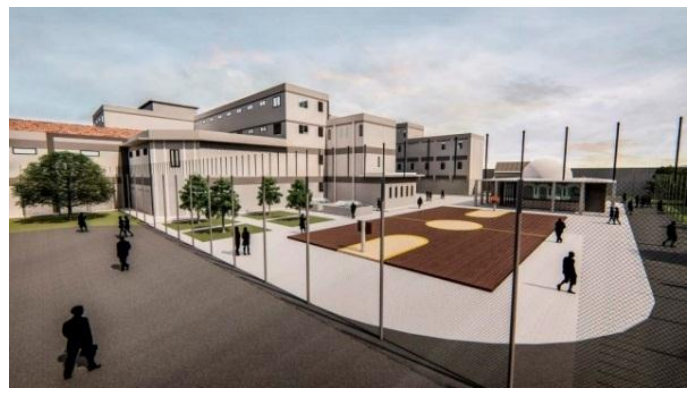

Gambar 16. Perspektif Eksterior Area Pembinaan 


\section{KESIMPULAN}

Lembaga Pemasyarakatan Kelas II yang dirancang untuk mengakomodasi kebutuhan sistem pemasyarakatan bagi narapidana yang membutuhkan ketenangan dan keamanan dalam aktivitas pembinaan dan instropeksi diri, memerlukan rancangan bangunan yang lebih efektif dan efisien dengan memperhatikan karakteristik lingkungan internal maupun eksternal pada Lembaga Pemasyarakatan.

Prinsip sistem keamanan dalam perancangan bangunan Lapas kelas II di Surakarta merupakan sebuah metode yang tepat untuk diterapkan karena sesuai dengan kriteria bangunan lapas yang memperhatikan aspek pengamanan bangunan meliputi pengamanan fisik seperti perencanaan elemen arsitektural, perencanaan struktur dan utilitas, perencanaan tapak, perencanaan tampilan, yang didukung ataupun tereduksi dengan adanya penggunaan teknologi keamanan namun tetap memperhatikan peraturan pembangunan Lapas. Maka dapat menciptakan konsep desain bangunan Lapas yang memunculkan citra bangunan Lapas baru.

\section{REFERENSI}

Angkasa, R. R., Nugroho, Rachmadi, \& Pradnya, D. S. (2014). P ENGEMBANGAN KOMPLEK L EMBAGA PERMASYARAKATAN K ELAS IIA. Arsitektura Universitas Sebelas Maret, 12.

B. Prasetya, Andhika., Purnomo, M.D.E., \& Widodo, A. S. (2015). Lembaga P Emasyarakatan Anak Daerah I Stimewa Yogyakarta Sebagai Wadah Pembinaan Kebersamaan Untuk Menumbuhkan. Arsitektura Universitas Sebelas Maret, 13.

Bapppeda Kota Surakarta. (2016). Sistem Informasi Pembangunan Daerah Kota Surakarta. Kota Surakarta.

Direktorat Jendral Pemasyarakatan. (2018). Jumlah Penghuni Rutan Kelas I Surakarta. Retrieved March 12, 2018, from

http://smslap.ditjenpas.go.id/public/grl/det ail/monthly/upt/db5f98b0-6bd1-1bd1c4ce-313134333039
Kementrian Sekertaris Negara Republik Indonesia. Undang Undang Republik Indonesia Nomor 12 Tentang Pemasyarakatan (1995). Jakarta.

Menteri Kehakiman Republik Indonesia. Keputusan Menteri Kehakiman Republik Indonesia No: M.02-PK.04.10 Tentang Pola Pembinaan Narapidana/Tahanan (1990). Jakarta.

National Crime Prevention Council. (2008). Crime Prevention Through Environmental Design Guidebook. Singapore: Department Affairs Public.

Phillips, Todd S., Kliment, Stephen A., \& Griebel, M. A. (2003). Building Type Basics For Justice Facilities. Canada: John Wiley and Sons.Inc.

Purbaya, A. A. (2017). 11 Lapas dan 18 Rutan di Jateng Kelebihan Penghuni. Retrieved May 7, 2018, from https://news.detik.com/berita-jawatengah/d-3499431/11-lapas-dan-18-rutandi-jateng-kelebihan-penghuni

Sutisna, N. (2017). Dirjen Lapas Kemenkum HAM: Idealnya Indonesia Butuh 1.000 Lapas. Retrieved March 29, 2018, from https://nasional.tempo.co/read/876174/dir jen-lapas-kemenkum-ham-idealnyaindonesia-butuh-1-000lapas/full\&view $=$ ok. 